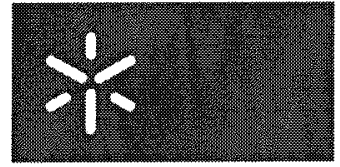

Und

[Cl-26]

Silva, H.M.R.D., Pais, J.C., Pereira, P.A.A.

"Comparison between tensile, stiffness and fatigue life tests results"

6th International RILEM Symposium on Performance Testing and Evaluation of Bituminous Materials, Zurich, Switzerland, 2003, p. 205-211 


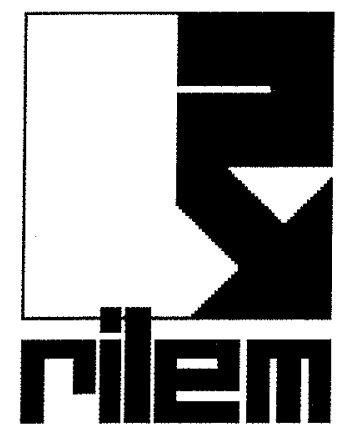

Proceedings

PRO 28

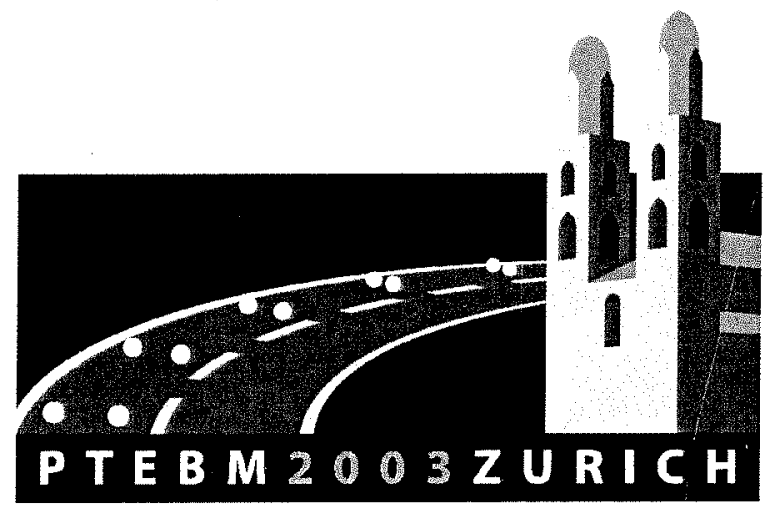

P TEB M 2003 Z U R I C H

\section{Performance Testing and Evaluation of Bituminous Materials PTEBM'03}

Proceedings of the

$6^{\text {th }}$ International RILEM Symposium

Edited by M.N. Partl 


\section{Contents}

\section{SESSION 1: SPECIAL SESSION}

Moderator: Manfred N. Partl

\section{RILEM TC 182-PEB CONTRIBUTIONS}

1. Activity of RILEM TC 182-PEB TG1 “Binders": $2^{\text {nd }}$ RILEM round robin test on binder rheology

D. Sybilski and A. Vanelstraete

2. Fatigue of bituminous mixtures: different approaches and RILEM group contribution

H. Di Benedetto, C. De La Roche, H. Baaj, A. Pronk and R. Lundström

3. RILEM - Interlaboratory tests on performance prediction of pavements

H. Piber and M.N. Partl

\section{SESSION 2: CHARACTERIZATION OF BITUMINOUS BINDERS AND MASTIC}

\section{Moderator: Ilan Ishai}

4. A new high-frequency torsional rheometer for bituminous binders

L.D. Poulikakos, M.B. Sayir and M.N. Partl

5. Dynamic and transient testing of asphalt binder and paving mix

L. Zanzotto, O.J. Vacin and J. Stastna

6. Precision of bituminous binder rheology tests in the $2^{\text {nd }}$ RILEM round robin test

D. Sybilski and A. Vanelstraete

7. Performance evaluation system for bituminous binders

A. Vanelstraete and W.Teugels

8. Rheological characterisation of some (polymer modified) bitumen and bitumen-filler system at compaction and in-service temperatures

$M$. van de Ven and K. Jenkins

9. The use of direct tension tests for the assessment of low temperature properties of bituminous binders

S. Largeaud, H. Raffegeaud, B. Simaillaud, B. Eckmann, E. Sauger,

S. Ollier, G. Hervé, L. Wendling, J. Pascot, J.C. Vaniscote and D. Chabert

10. Empirical and fundamental rheological properties of polymer modified bitumens

G.D. Airey and B. Rahimzadeh 
11. Evaluation of fatigue properties of bituminous binders

J.-P. Planche, D.A. Anderson, G. Gauthier, Y.M. Le Hir and D. Martin

12. Rheological characterization of bituminous binder to predict pavement rutting

Y. Le Hir, D.A. Anderson, J.-P. Planche and D. Martin

13. Practical test methods for measuring the zero shear viscosity of bituminous binders

J. De Visscher and A. Vanelstraete

\section{SESSION 3: AGING}

\section{Moderator: Hussein Bahia}

14. Accelerated aging tests for asphalt concretes Y. Hachiya, K. Nomura and J. Shen

15. Testing of performance properties of asphalt mixes for thin wearing courses

J. Judycki and P. Jaskuła

16. Effectiveness and durability of rejuvenating agents

I. Schiavi, M. Nunn, C. Nicholls and P. Chambers

17. Development of a new methodology for characterization of polymer modified bitumens ageing by infrared microspectrometry imaging

V. Mouillet, J. Lamontagne, F. Durrieu, J. Kister and D. Martin

18. Development of an accelerated durability assessment procedure for high modulus base (HMB) materials

G.D. Airey, Y.K. Choi, A.C. Collop and R.C. Elliott

19. Short- and long-term ageing of bituminous binders - Simulation with RCAT method

A.F. Verhasselt

\section{SESSION 4: BITUMINOUS BINDER-AGGREGATE INTERACTION \\ Moderator: Dariusz Sybilski}

20. The influence of aggregate on moisture susceptibility in terms of asphalt-aggregate interactions

S.-C. Huang, J.F. Branthaver and R.E. Robertson

21. Adhesive activity of bitumen with adhesion agent and its influence on asphalt concrete water-resistance

V.A. Zolotarev and A.A. Pissanko

22. Causes of premature ravelling failure of porous asphalt

J.L.M. Voskuilen and P.N.W. Verhoef

23. Predicting the early life skid resistance of asphalt surfacings

W.D.H. Woodward, A.R. Woodside and J.H. Jellie 
24. Comparison between tensile, stiffness and fatigue life test results

H.M.R.D. Silva, J.C. Pais and P.A.A. Pereira

25. Investigation of problems in binder extraction from conventional and rubber modified asphalt mixtures

O. Sirin and M. Tia

\section{SESSION 5: MIX DESIGN \\ Moderator: Yves Brosseaud}

26. Influence of curing on cold mix mechanical performance

J.-P. Serfass, J.-E. Poirier, J.-P. Henrat and X. Carbonneau

27. Evaluation of improved porous asphalt by various test methods

S. Takahashi, L.D. Poulikakos and M.N. Partl

28. Study of the aggregate gradation for the pervious asphalt concrete

L. Momm, E. Meurer Filho and L.L. Bariani Bernucci

29. Gyratory compaction: influence of angle on stability and stiffness characteristics

N. Ulmgren

30. Comparison of Marshall and SUPERPAVE design methods, evaluation of wheel tracking test of asphalt mixtures designed by both methods

M. Varaus

31. Semi-circular bending test to asses the resistance against crack growth

R. Hofman, B. Oosterbaan, S.M.J.G. Erkens and J. van der Kooij

32. The spatial approach of hot mix asphalt

M.F.C. van de Ven, J.L.M. Voskuilen and F. Tolman

33. Expression de l'incertitude sur les résultats d'essais dans les laboratoires routiers

M. Saubot

34. The influence of fine aggregate on the bituminous mixture mechanical behaviour

J.C. Pais, P.P.A. Pereira and L.G. Picado-Santos

35. Effect of asphalt film thickness on low temperature cracking and rutting

Y. Tasdemir, T.S. Vinson and E. Agar

36. New developments in the PRADO volumetric mix design

L. Francken, A. Vanelstraete, D. Léonard and O. Pilate

\section{SESSION 6: MODULUS \\ Moderator: Ann Vanelstraete}

37. Comparison of analysis techniques to obtain modulus and phase angle from sinusoidal test data

T. Pellinen and B. Crockford

38. Evaluation of the indirect tensile stiffness modulus test

X. Carbonneau, Y. Le Gal and P. Bense 
39. Permanent deformation and complex modulus : two different characteristics from a unique test

M. Neifar, H. Di Benedetto and B. Dongmo

40. Determination of viscoelastic properties from the indirect tensile stiffness modulus (ITSM) test

A.C. Collop and G.D. Airey

41. Viscoelastic linearity limits for bituminous materials

G.D. Airey, B. Rahimzadeh and A.C. Collop

42. Surface roughness of asphalt concrete and its mechanical behavior

L. Momm, C. De La Roche and F.A.A. Domingues

\section{SESSION 7: FATIGUE}

\section{Moderator: Hervé Di Benedetto}

43. Assessing the potential in fatigue of a dense wearing course emulsified bitumen macadam

H.A. Khalid

44. Flexural beam fatigue properties of airfield asphalt mixtures containing styrene-butadiene based polymer modifiers

K. Newman

45. Mode of loading on flexural fatigue laboratory properties of conventional and asphalt rubber mixes: a model validation

J.B. Sousa, J.C. Pais, P. Pereira and G. Way

46. Analysis of fatigue performance of asphalt mixtures. Relationship between toughness and fatigue resistance

F. Pérez Jiménez, R. Miró Recasens and J. Cepeda Aldape

47. Prediction of the intrinsic damage during bituminous mixes fatigue tests

D. Bodin, C. De La Roche, J.-M. Piau and G. Pijaudier-Cabot

48. Determination of fracture parameters of asphalt mixes by the repeated indirect tensile test

F.O. Martínez and S. Angelone

49. Fatigue of mixes : an intrinsic damage approach

H. Baaj, H. Di Benedetto and P. Chaverot

50. Asphalt material fatigue test under cyclic loading: the lengthening of samples as a way to characterize the material damage experiments and modelling

Y. Lefeuvre, C. De La Roche and J.-M. Piau

51. Fatigue and healing characteristics of bitumens studied using dynamic shear rheometer

X. Lu, H. Soenen and P. Redelius

52. Influence of rest time on recovery and damage during fatigue tests on bituminous composites

D. Breysse, C. De La Roche, V. Domec and J.J. Chauvin 
53. New approach for the fatigue characterisation of bituminous binders

S. Tóth and R. Perlaki

\section{SESSION 8: TEMPERATURE INDUCED CRACKING Moderator: Ulf Isacsson}

54. Influence of polymer modification on low-temperature properties of bituminous binders and mixtures

X. Lu, U. Isacsson and J. Ekblad

55. Test methods for the behavior of bituminous binders at low temperature

R. Gubler, M.N. Partl, M. Riedi and C. Angst

56. Properties of bituminous mixtures at low temperatures and relations with binder characteristics

F. Olard, H. Di Benedetto, A. Dony and J.-C. Vaniscote

57. Performance indicators for low temperature cracking

H. Soenen and A. Vanelstraete

58. Fissuration à basse température des enrobés bitumineux - essai de retrait thermique empêché et émission acoustique

S. Cordel, H. Di Benedetto, M. Malot, P. Chaverot et D. Perraton

59. Thermomechanical analysis of aged asphalt pavements at low temperature

T. Pucci, A.-G. Dumont, H. Di Benedetto

\section{SESSION 9: PERMANENT DEFORMATION Moderator: Chantal de la Roche}

60. Non-uniqueness of micro deformation of asphalt concrete

L. Wang and C.S. Chang

61. Model for forecasting ruts in rutting tester

A. Szydło and P. Mackiewicz

62. Simple performance test for permanent deformation evaluation of asphalt mixtures

K.E. Kaloush, M.W. Witczak and B.W. Sullivan

63. Laboratory testing to develop a non-linear viscoelastic model for rutting

of asphalt concrete

F. Long and C.L. Monismith

64. Complex modulus and creep susceptibility of asphalt mixture

J.M.M. Molenaar and A.A.A. Molenaar

65. Asphalt flow improvers -a new technology for reducing mixing temperature of asphalt concrete mixes with high resistance against permanent deformation K.-W. Damm

66. Evaluating creep compliance of asphaltic paving mixtures using a

hollow-cylinder tensile tester

W.G. Buttlar and G.G. Al-Khateeb 
67. Comprehensive material characterization of asphalt concrete in tension based on a viscoelastoplastic model

G. Chehab, Y.R. Kim, M.W. Witczak and R. Bonaquist

\section{SESSION 10: FIELD AND ACCELERATED PAVEMENT TESTING}

\section{Moderator: Jorge Sousa}

68. Hot mix asphalt design prediction and field performance, an Arizona study

G.B. Way, J. Sousa and K. Kaloush

69. Evaluation of the effect of tack coats. LCB shear test

R. Miró Recasens, F. Pérez Jiménez and J.M. Borras Gonzalez

70. Validation and refinement of the transportek wheel tracking test in the South African guidelines for hot mix asphalt

F. Long and B. Verhaeghe

71. Permanent deformation and fatigue evaluation of asphalt concrete mixes

72. Asphalt mix design for Cape Town International Airport using

J. T. Harvey, I. Guada, D. Hung, C.L. Monismith, F. Long

K. Jenkins, F.J. Pretorius, F. Hugo and R. Carr

73. Permanent deformations in asphalt concrete layers in Brazil

F.P. Gonçalves, J.A. Ceratti and L.B. Bernucci

SESSION 11: STRUCTURAL PAVEMENT DESIGN AND

\section{Moderator: Herald Piber}

74. Harmonised European test methods J.P.J. van der Heide and J.C. Nicholls

75. Development and use of functional asphalt tender specifications

R.C. van Rooijen and A.H. de Bondt

76. Performance - Related testing of asphaltic plug joint systems in Germany

77. Damage analysis for flexible pavements at high and low temperatures using visco-elastic hybrid FEM

A. Moriyoshi, M.N. Partl, H. Denpouya and S. Takano

78. Resistance to crack-growth and fracture of asphalt mixture

79. Determination of constitutive model parameters to simulate asphalt mixture response J. Molenaar, X. Liu and A.A.A. Molenaar 


\title{
COMPARISON BETWEEN TENSILE, STIFFNESS AND FATIGUE LIFE TESTS RESULTS
}

\author{
Hugo D. Silva, Jorge C. Pais and Paulo A.A. Pereira \\ University of Minho, Department of Civil Engineering, Portugal
}

\begin{abstract}
A laboratory mechanical test is being implemented in the University of Minho to evaluate the asphalt-aggregate interaction. This test measures the tensile properties of the bituminous mixture in the interface between the asphalt and the aggregates. By using the tensile test it is intended to observe how the asphalt-aggregate interaction influences the mechanical properties of the bituminous mixtures, namely, stiffness modulus and fatigue life. The tensile test results must have a good correlation to the ones of the stiffness and fatigue life tests in order to assure that the tensile test can be used to investigate the influence of the asphalt-aggregate interaction in the mechanical behaviour of the bituminous mixtures. Thus, this paper presents the comparison between the tensile strength results and the fatigue life and stiffness modulus results of the corresponding mixtures.
\end{abstract}

\section{Introduction}

A laboratory test for the characterization of the asphalt-aggregate interaction is being developed at the University of Minho. This test evaluates the tensile strength of the bituminous mixture in the interface between the asphalt and the aggregates.

Since the mechanical mix behaviour depends on the asphalt-aggregate interaction, the tensile test can be used to evaluate not only the asphalt-aggregate interaction but also its influence in the performance of the whole mixture. So, to investigate the selection of the tensile test to observe the influence of the asphalt-aggregate interaction in the mixture behaviour, standard fatigue and stiffness tests were executed on bituminous mixtures with different aggregate gradations and correlated to the results of the tensile test.

The tests were performed in bituminous mixtures used in wearing and base courses. For each type of mixture, five mixtures were defined, by changing the gradation curve (from more to fewer fines). With the aim of evaluating stiffness and fatigue, tests were executed on a four point bending beam on controlled strain, whereas for the evaluation of the tensile strength, tests were performed in simple tension.

The main objective of this paper is to analyse if the tensile test implemented in the University of 
Minho simulates accurately the mechanical behaviour of a bituminous mixture, including not only the asphalt-aggregate interaction but also the stiffness and the fatigue.

The achievement of a good correlation between tensile, stiffness and fatigue life tests results demonstrates the capabilities of the tensile test to investigate the influence of asphalt-aggregate interaction in the mechanical behaviour of a bituminous mixture.

\section{Material characterization}

In this study two types of bituminous mixtures were used: a dense graded bituminous mixture for base courses and a bituminous mixture for wearing courses, following the Portuguese normalization (APORBET, 1998). Based on each aggregate gradation, more four mixtures were used: two mixtures where the gradation curve is below and two mixtures where the gradation curve is above the gradation curve defined by the Portuguese normalization. These four gradation curves were defined by changing the amount of aggregates in the sieves with a dimension lower than $2.000 \mathrm{~mm}$.

Thus, the gradation curve proposed by the Portuguese normalization for wearing courses was used to produce mix number 1 (more fines) to 5 (fewer fines), as presented in Table 1, and the gradation curve proposed by the Portuguese normalization for base courses was used to define mixes 6 (more fines) to 10 (less fines), as presented in Table 2.

Table 1. Aggregate gradations used for wearing course bituminous mixtures $(0 / 14)$

\begin{tabular}{|c|c|c|c|c|c|}
\hline \multirow{2}{*}{$\begin{array}{c}\text { Sieve } \\
\text { dimension (mm) }\end{array}$} & \multicolumn{5}{|c|}{ Percentage of material passing } \\
\cline { 2 - 6 } & Mix 1 & Mix 2 & Mix 3 & Mix 4 & Mix 5 \\
\hline 19.000 & 100.0 & 100.0 & 100.0 & 100.0 & 100.0 \\
\hline 12.500 & 84.0 & 84.0 & 84.0 & 84.0 & 84.0 \\
\hline 9.500 & 71.3 & 71.3 & 71.3 & 71.3 & 71.3 \\
\hline 4.750 & 55.4 & 55.4 & 55.4 & 55.4 & 55.4 \\
\hline 2.000 & 36.4 & 36.4 & 36.4 & 36.4 & 36.4 \\
\hline 0.850 & 30.6 & 29.7 & 23.7 & 24.7 & 22.4 \\
\hline 0.425 & 27.0 & 25.5 & 15.6 & 17.2 & 13.3 \\
\hline 0.180 & 15.7 & 14.0 & 10.5 & 9.3 & 7.1 \\
\hline 0.075 & 8.7 & 6.9 & 7.4 & 4.3 & 3.3 \\
\hline
\end{tabular}

Table 2. Aggregate gradations used for base course bituminous mixtures $(0 / 19)$

\begin{tabular}{|c|c|c|c|c|c|}
\hline \multirow{2}{*}{$\begin{array}{c}\text { Sieve } \\
\text { dimension (mm) }\end{array}$} & \multicolumn{5}{|c|}{ Percentage of material passing } \\
\cline { 2 - 6 } & Mix 6 & Mix 7 & Mix 8 & Mix 9 & Mix 10 \\
\hline 25.000 & 100.0 & 100.0 & 100.0 & 100.0 & 100.0 \\
\hline 19.000 & 96.2 & 96.2 & 96.2 & 96.2 & 96.2 \\
\hline 12.500 & 80.0 & 80.0 & 80.0 & 80.0 & 80.0 \\
\hline 9.500 & 72.5 & 72.5 & 72.5 & 72.5 & 72.5 \\
\hline 4.750 & 59.2 & 59.2 & 59.2 & 59.2 & 59.2 \\
\hline 2.000 & 42.9 & 42.9 & 42.9 & 42.9 & 42.9 \\
\hline 0.850 & 36.3 & 35.2 & 30.8 & 28.4 & 25.7 \\
\hline 0.425 & 32.3 & 30.4 & 23.1 & 19.1 & 14.5 \\
\hline 0.180 & 18.5 & 16.7 & 13.7 & 10.2 & 7.7 \\
\hline 0.075 & 9.8 & 8.1 & 7.9 & 4.6 & 3.5 \\
\hline
\end{tabular}


Binder and air-void content for all mixtures are presented in Table 3. For each mixture studied, the binder content (optimum) was calculated using a formula based on the specific surface of the aggregates.

Table 3. Binder content, binder/filler ratio and air-void content of the mixtures studied

\begin{tabular}{|c|c|c|c|c|c|c|c|}
\hline Mix & $\begin{array}{c}\text { Binder } \\
\text { Content }\end{array}$ & $\begin{array}{c}\text { Binder/Filler } \\
\text { Ratio }\end{array}$ & $\begin{array}{c}\text { Air-void } \\
\text { Content }\end{array}$ & Mix & $\begin{array}{c}\text { Binder } \\
\text { Content }\end{array}$ & $\begin{array}{c}\text { Binder/Filler } \\
\text { Ratio }\end{array}$ & $\begin{array}{c}\text { Air-void } \\
\text { Content }\end{array}$ \\
\hline 1 & $6.0 \%$ & 0.69 & $1.3 \%$ & 6 & $6.0 \%$ & 0.61 & $4.9 \%$ \\
\hline 2 & $5.8 \%$ & 0.84 & $2.9 \%$ & 7 & $5.8 \%$ & 0.72 & $7.4 \%$ \\
\hline 3 & $5.8 \%$ & 0.78 & $1.2 \%$ & 8 & $5.8 \%$ & 0.73 & $4.0 \%$ \\
\hline 4 & $5.4 \%$ & 1.26 & $5.0 \%$ & 9 & $5.3 \%$ & 1.15 & $6.6 \%$ \\
\hline 5 & $5.2 \%$ & 1.58 & $7.7 \%$ & 10 & $5.1 \%$ & 1.46 & $10.8 \%$ \\
\hline
\end{tabular}

The different void content of the mixtures studied is due to their different workability, because the compaction method was always the same. It is important to observe the air-void content influence in the results obtained (Sousa et al, 1998).

In the Table 3, it is also presented the Binder/Filler ratio, were the Filler was considered to be the material passed in the sieve with a dimension of $0.075 \mathrm{~mm}$.

\section{Stiffness and fatigue life}

Four point bending beam tests were conducted according to the AASHTO TP 8-94. They are intended to simulate pavement distress due to traffic loads during its expected design life. They also determined fatigue life and stiffness modulus of the beams. Fatigue life is defined as the number of cycles until a $50 \%$ decrease of the initial stiffness of the test beam is achieved (Pais, 1999). Tests were undertaken at $25^{\circ} \mathrm{C}$ and at $10 \mathrm{~Hz}$ frequency rate of loading. Stiffness was obtained for a strain level of $150 \times 10^{-6}$.

Figure 1 presents stiffness modulus of all the bituminous mixtures studied as a function of applied frequency.

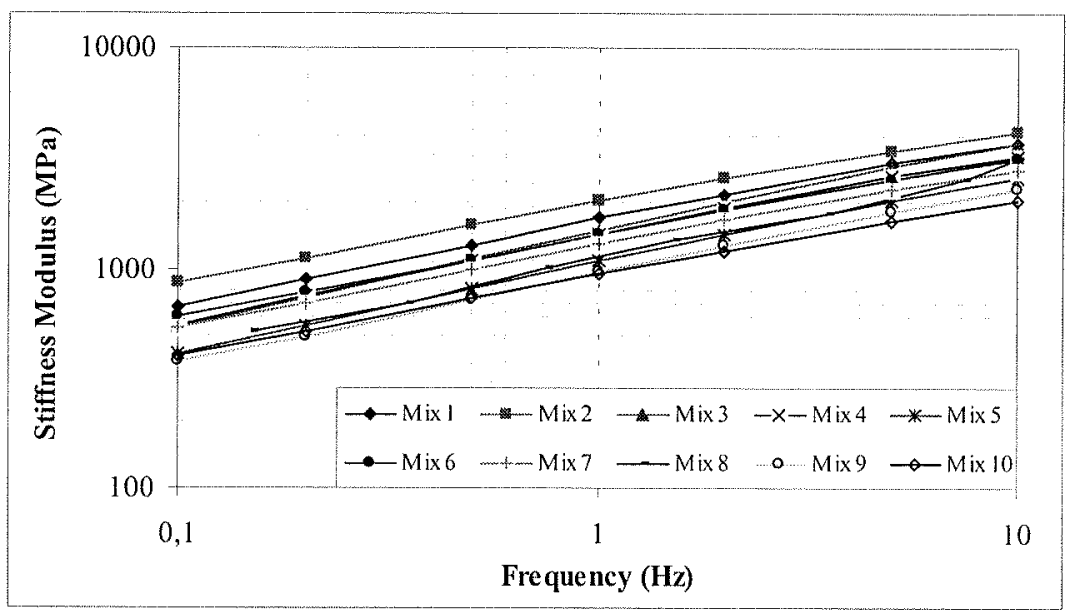

Figure 1. Stiffness modulus plotted against frequency $\left(\right.$ temperature $\left.=25^{\circ} \mathrm{C}\right)$ 
In Figure 2 the stiffness modulus at $10 \mathrm{~Hz}$ is plotted to shows the ranking of studied mixes and it can be concluded that the increase of fines increases the stiffness modulus. The horizontal lines represent the average value for each type of mix.

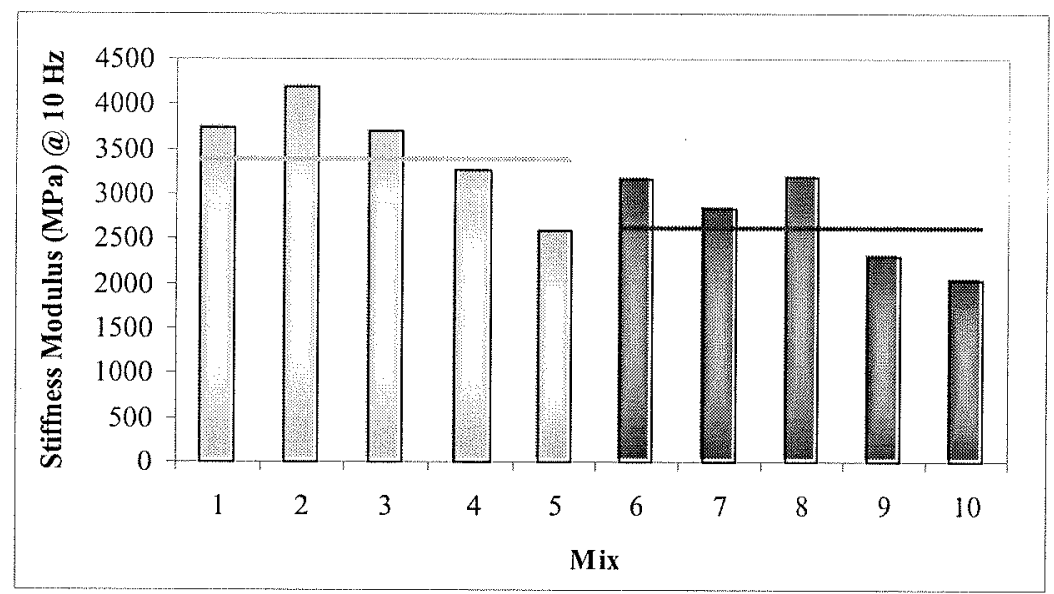

Figure 2. Stiffness modulus at $10 \mathrm{~Hz}$ (temperature $=25^{\circ} \mathrm{C}$ )

The ranking of the bituminous mixtures in the fatigue tests can be found in Figure 3 where the fatigue life at $100 \times 10^{-6}$ is presented. The analysis of this figure shows that the decrease of fine aggregates increases the fatigue life.

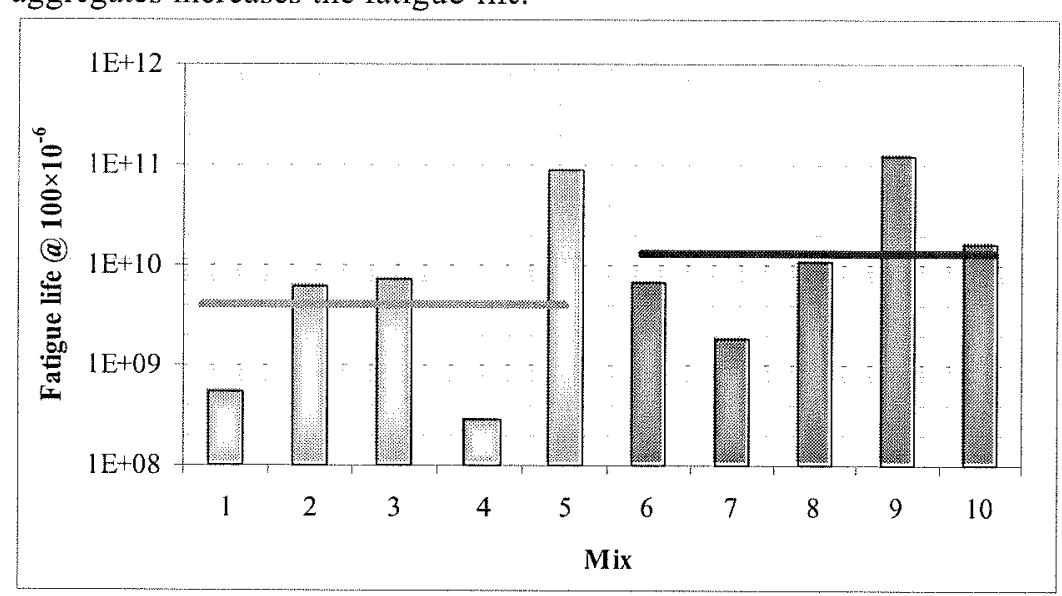

Figure 3. Fatigue life at a strain of $100 \times 10^{-6}\left(\right.$ temperature $\left.=25^{\circ} \mathrm{C}\right)$

\section{Tensile strength}

The test used to evaluate the tensile strength of the bituminous mixtures was a simple tension test. The type of loading is like the one used to evaluate the asphalt-aggregate interaction. In Figure 4 it can be seen a specimen being tested in simple tension. 


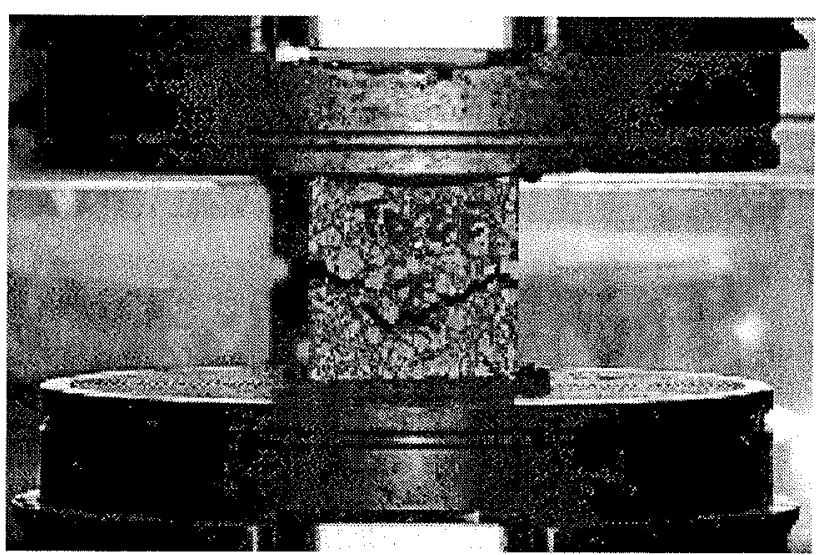

Figure 4. Specimen used in the tensile test being tested

In Figure 5, one can observe the typical result of a tensile test. The specimens were tested in simple tension at a constant deformation rate of $2 \mathrm{~mm} /$ minute, quickly reaching rupture and the maximum value of resistance. The overall results of the tensile tests regarding the influence of mastic gradation are presented in Figures 6 and 7. The fact that these tests had been done in specimens prepared with bituminous mixture should be remembered.

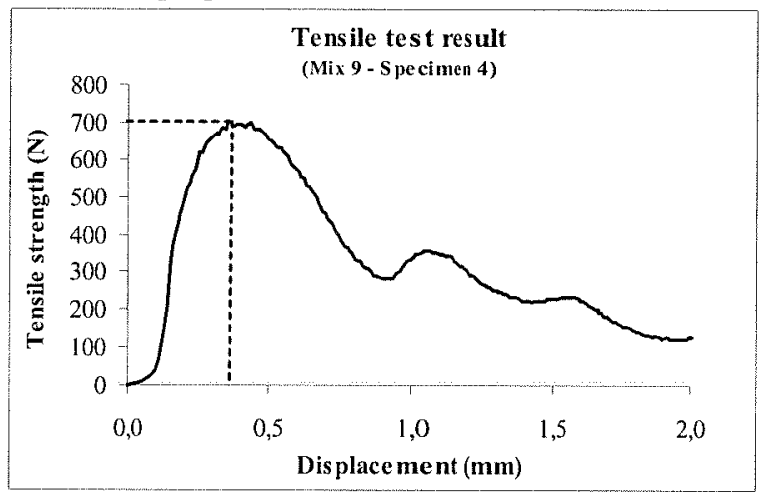

Figure 5. Typical result of a tensile test (temperature $=25^{\circ} \mathrm{C}$ )

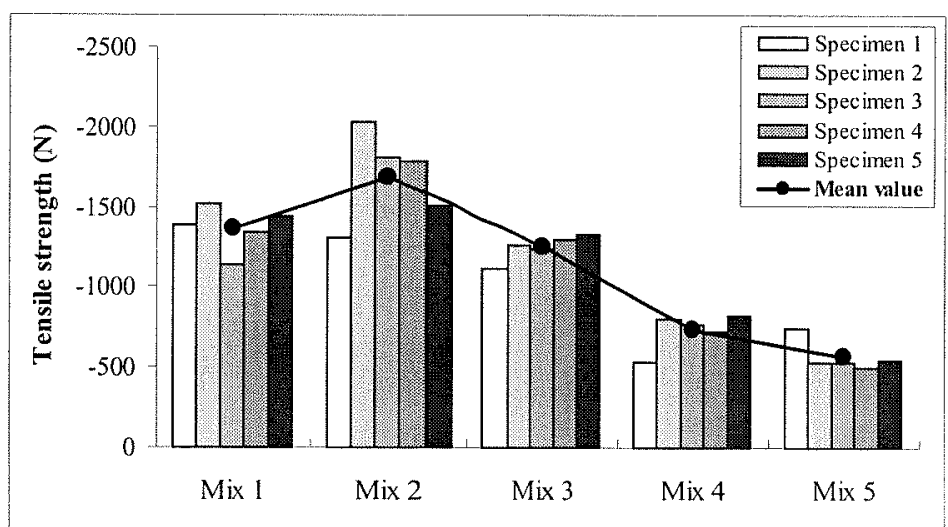

Figure 6. Results of the tensile test on the wearing course bituminous mixtures $(0 / 14)$ 


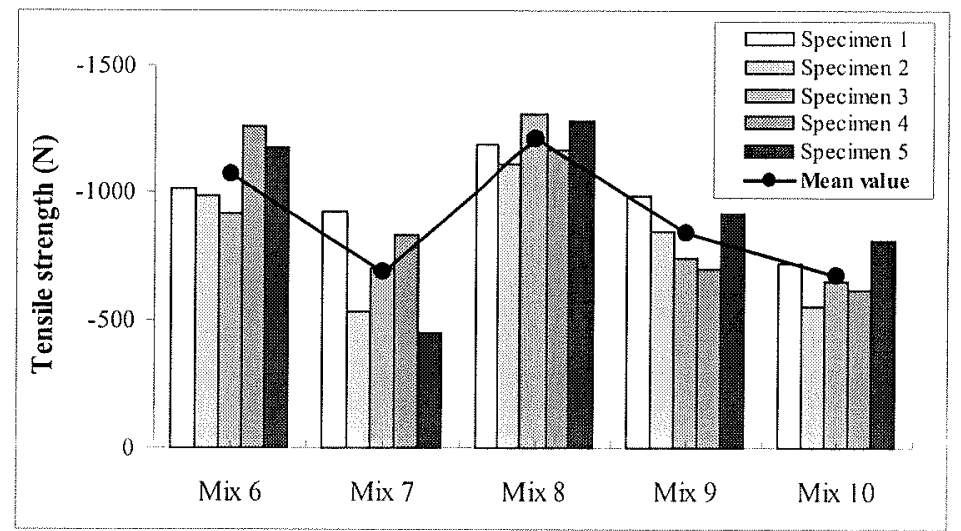

Figure 7. Results of the tensile test on the base course bituminous mixtures $(0 / 19)$

The tensile test has been shown to be an option to predict the mechanical behaviour of a mix. The test reproducibility is good. The simplicity and speed of production and of test for a large number of specimens make this tensile test a good choice for evaluation and study of the mechanical behaviour of a mix. It was observed that the mixtures with higher mastic content (associated with elevated binder and fines content) had the bigger tensile strength.

Finally, the results obtained in the tensile test have been correlated to the stiffness modulus and the fatigue life of the corresponding mixtures, as shown in Figures 8 and 9. These correlation graphics correspond to the comparison between the results presented in Figures 2, 3,6 and 7, and they will permit to analyse if the tensile test simulates accurately the mechanical behaviour of a bituminous mixture.

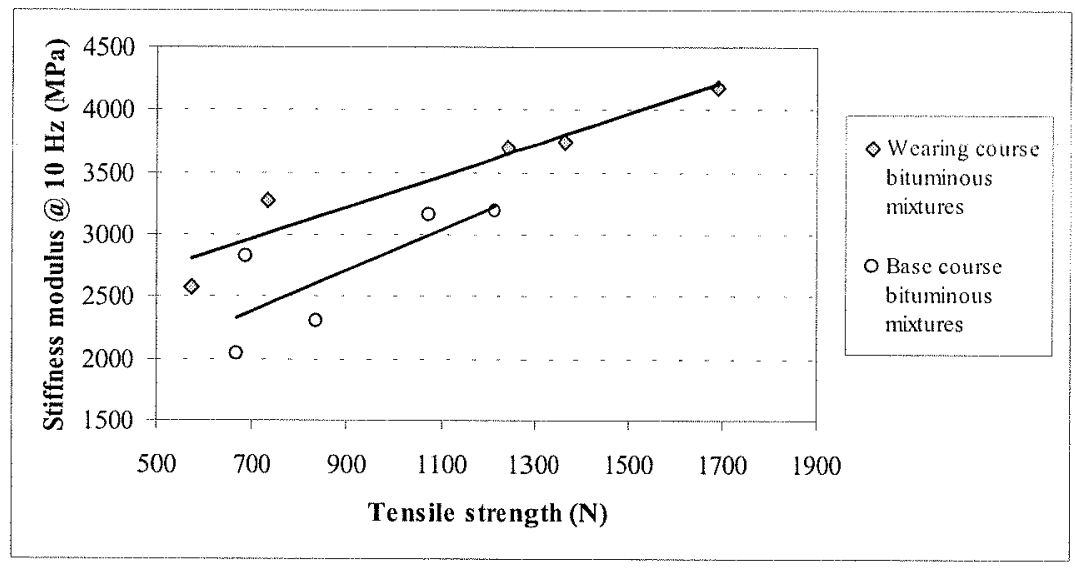

Figure 8. Correlation between the tensile strength and the stiffness modulus 


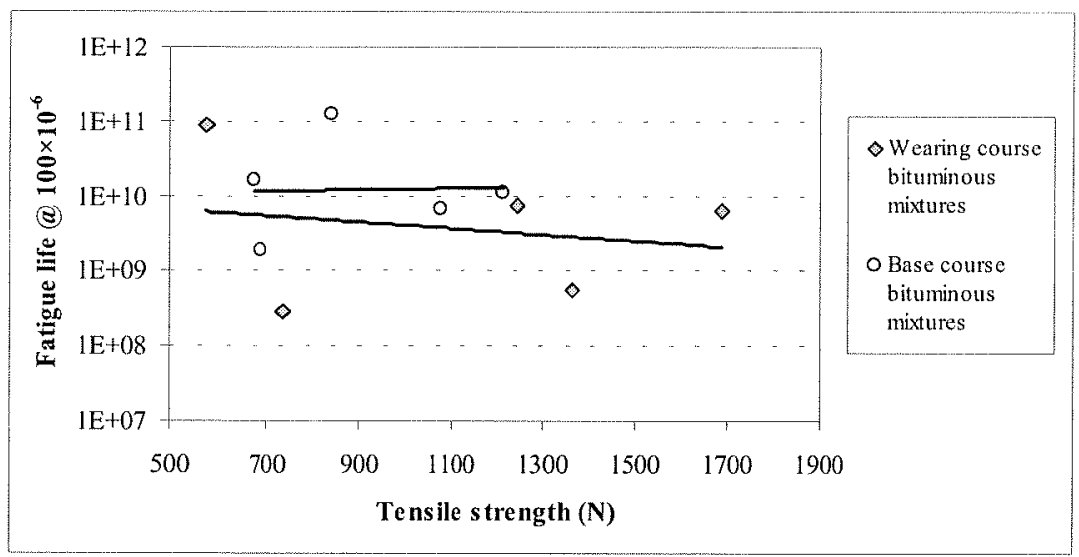

Figure 9. Correlation between the tensile strength and the fatigue life

\section{Conclusions}

This paper presented an evaluation of fatigue and stiffness performance of bituminous mixtures with different aggregate gradations based on the ones proposed by the Portuguese normalization for wearing and base courses. Moreover, the results of a tensile test, similar to the one developed in the University of Minho to evaluate the interaction between the asphalt and the aggregates of a bituminous mixture, are also presented.

The comparison between the tensile test and the stiffness and fatigue tests allows us to evaluate the capabilities of the tensile test to investigate the influence of interaction in the mechanical behaviour of a bituminous mixture.

asphalt-aggregate

From the analysis of each test and from the comparison between them, the following conclusions can be drawn:

- The increase of fine aggregates tends to increase the tensile strength and to decrease the fatigue life;

- The results of the tests are dependent on the air-void content of the mixtures: usually the reduction in the air-void content implies a better behaviour of the bituminous mixture;

- The correlation between the results of the tensile test and the stiffness modulus of the same mixture is very good;

- The correlation between the results of the tensile test and the fatigue life of the same mixture is poor;

- A repetitive tensile test will be developed, in the future, in order to simulate in a more accurate way the fatigue behaviour of bituminous mixtures.

\section{References}

1. APORBET, Misturas Betuminosas. Contribuição para a Normalização do Fabrico e Aplicação, Lisboa, (1998).

2. Sousa, J.B., Pais, J.C., Prates, M., Barros, R., Langlois, P. \& Leclerc, A.M., "Effect of Aggregate Gradation on Fatigue Life of Asphalt Concrete Mixes" in Transportation Research Board, (1998).

3. Pais, J.C., Reflective Cracking in Flexible Pavement Overlay Design (in Portuguese). Ph.D. Thesis. University of Minho, Braga, Portugal, (1999). 